\title{
SRAP and ISSR Molecular Markers-trait Associations in Sorghum Genotypes
}

\author{
Khaled, A.G.A.; G.A.R. El-Sherbeny and Hadeer S. A. Abdelaziz \\ Department of Genetics, Faculty of Agriculture, Sohag University, 82786 Sohag, Egypt \\ *Email: abdelsabour.khaled@agr.sohag.edu.eg
}

Received on: $24 / 2 / 2019$

Accepted for publication on: 27/2/2019

\begin{abstract}
:
In order to better understand the relationship genotype-phenotype, markertrait associations in 7 sorghum genotypes were studied using a set of 75 DNAbased molecular markers (39 SRAP and 36 ISSR polymorphic markers). SRAP and ISSR analysis showed similar average of the percentage of polymorphism $(\% \mathrm{P})$ which was 51.37 and $53.03 \%$, respectively, as well as the average of polymorphic information content (PIC) which was 0.17 and 0.16 , respectively. Moreover, the means of marker index (MI) were 0.68 and 0.73 for SRAP and ISSR markers, respectively. The result of di-nucleotide repeat ISSR (UBC-846 belonged to (CA) repeats) primers represented the highest levels of polymorphism of about $70 \%$. The SRAP primer combinations ME4F-EM10R produced the highest level of $\% \mathrm{P}$ of $86 \%$, while the primers ME2F-EM8R produced the lowest level of $\%$ P of $25 \%$. Single-marker analysis (SMA) indicated that 4 SRAP markers linked to leaf area/plant, panicle length, 1000-Grain weight and grain yield/plant. The ISSRs markers; UBC-834.1 $1_{650 \mathrm{bp}}$ and UBC-834.1 ${ }_{700 \mathrm{bp}}$ were regarded as candidate markers, linked to leaf area/plant, panicle length, 1000-Grain weight and number of green leaves. The cluster analysis based on SRAP, ISSR and means of phenotypic data revealed similarity coefficient values ranged from 0.685 to $0.847,0.627$ to 0.882 , and from 0.878 to 0.978 , respectively. Similarity matrices generated by SRAP markers and ISSR showed a positive but insignificant correlation ( $\mathrm{r}=0.21, P \square 0.05)$.
\end{abstract}

Keywords: Sorghum, correlation, polymorphism, similarity.

\section{Introduction}

In Egypt, grain sorghum is an important cereal crop production after wheat, maize and rice. In 2014, the cultivated area of grain sorghum in Egypt was about 148,460 ha, producing about 804,000 tons with an average productivity of 5.42 ton/ha according to (FAOSTAT, 2017). Most of grain sorghum cultivated area in Egypt is concentrated in Assiut and Sohag governorates (Upper Egypt), where grain sorghum is more tolerant to drought and temperature stress than maize.
For breeding program, breeders look for the existence of genetic variability for the characters of interest (Jahufer and Gawler, 2000). This is due to the critical role of genetic variability in determining the amount of progress to be made by selection. Hence, estimation of the extent and pattern of genetic variability existing in the available germplasm is essential to breeders.

Morphological markers have been used to estimate genetic diversity in sorghum landraces elsewhere (Abdi et al., 2002; Ayana et al., 2000; Bucheyeki et al., 2009) and histori- 
cally in Mendelian analysis of discrete morphological traits (Doggett, 1988). However, morphological markers are greatly influenced by environmental factors (Ayana et al., 2000). Molecular markers are not influenced by environmental conditions for this reason these markers are decisive and more efficient for selection in breeding programs as well as to assess genetic diversity amongst. In relation to cost, easiness of use, consistency and repeatability of the results, inter simple sequence repeat (ISSR) and sequence related amplified polymorphism (SRAP) are techniques based on polymerase chain reaction (PCR) used to assess genetic diversity. SRAP is a molecular marker technique which could provide high polymorphism and plentiful information (Wang et al., 2009). SRAP targets functional genes and can be efficiently used for marker- assisted selection (MAS). ISSR markers are semi-arbitrary which used single forward primers with 1618 nucleotide length comprises repetitive units and anchors 2-4 arbitrary nucleotides at the $3^{\prime}$ or $5^{\prime}$ end. These techniques have been widely used in studies of genetic mapping, genetic diversity, evolution and molecular ecology (Yang et al., 1996). Therefore the objectives of this investigation were to estimate the performances of sorghum genotypes, the level of polymorphism and marker trait associations using phenotypic characters, SRAP and ISSR markers.

\section{Materials and Methods \\ Genetic Materials}

The grain sorghum (Sorghum bicolor L. Moench) used in this study (Table 1) were kindly provided by Sorghum Research Department, Field Crop Research Institute, Agricultural Research Center, Giza, Egypt.

Table 1. The pedigree and the origin of the studied sorghum genotypes.

\begin{tabular}{|c|l|c|c|l|c|}
\hline Genotype & \multicolumn{1}{|c|}{ Lines Pedigree } & Origin & Genotype & Testers Pedigree & Origin \\
\hline $\mathbf{L}_{\mathbf{1}}$ & SPST-B-92005 & India & $\mathbf{T}_{\mathbf{1}}$ & MR-48212 & India \\
\hline $\mathbf{L}_{\mathbf{2}}$ & BKFR-89 & Zambia & $\mathbf{T}_{\mathbf{2}}$ & SGL-87 & Mexico \\
\hline $\mathbf{L}_{\mathbf{3}}$ & SPRU-B-92007 & India & $\mathbf{T}_{\mathbf{3}}$ & ICSR-92014 & India \\
\hline $\mathbf{L}_{\mathbf{4}}$ & SPMD-B-92025 & India & & & \\
\hline
\end{tabular}

\section{Field Experimental Design:}

The genotypes (four maintainer and three restorer lines) were sown on $21^{\text {th }}$ June, 2017 in a Randomized Complete Block Designs (RCBD) with three replications. Each replication contained 20 plots, each plot consisted of two rows with $4 \mathrm{~m}$ long, $60 \mathrm{~cm}$ apart between rows and $15 \mathrm{~cm}$ between hills within a row. After full emergence the seedlings were thinned to two plants per hill before the first irrigation, three weeks after sowing.
Plants were irrigated every 15 days. The agricultural practices were followed as recommended.

\section{Traits Definitions}

The following agronomic traits were recorded as the mean of ten random guarded plants in each plot; days to $50 \%$ flowering, plant height $(\mathrm{cm})$, number of green leaves pre harvest, leaf area/plant (leaf length $\mathrm{x}$ leaf breadth $\mathrm{x} 0.75 \mathrm{x}$ no. of leaves/plant, where 0.75 is a constant factor), panicle length $(\mathrm{cm})$, panicle width $(\mathrm{cm})$, 
1000-grain weight $(\mathrm{g})$ and Grain yield / plant (g).

\section{Analysis of variance}

Data was subjected to analysis of variance in a randomized complete block design (RCBD) according to Gomez and Gomez (1984). The mean squares of genotypes and replications for all studied traits were tested for significance according to the F-test (data not shown). The forms of the analysis of variance were as outlined by Cochran and Cox (1957).

\section{DNA extraction and PCR proce- dure}

Fresh young leaves of seven parental sorghum plants were harvested and immediately ground in extraction buffer using cetyltrimethyl ammonium bromide (CTAB) protocol as described by Porebski et al. (1997). For each genotype, 0.2 of ground leaf tissue was suspended in $2 \mathrm{ml}$ of extraction buffer (20 mM of EDTA, 0.1 $\mathrm{M}$ of Tris-HCL, 1.4 of Nacl, $2 \%$ CTAB, $1 \%$ of PVP). The DNA pellet was then suspended in $100 \mu \mathrm{l}$ of TE buffer. Genomic DNA was diluted 10 -fold in water prior to 35 cycles of PCR amplification.

The PCR assays were performed for SRAP and ISSR markers in a $20 \mu \mathrm{l}$ volume containing $0.2 \mu \mathrm{l}$ of Go Taq polymerase, $3.5 \mu 1$ of primer
(8 pmol), $4 \mu 15 \mathrm{X}$ green buffer, $2 \mu 1$ $\mathrm{Mgcl}_{2}, 2 \mu \mathrm{ldNTPs}(2.5 \mathrm{mM}), 5.3 \mu \mathrm{l}$ of free nuclease water and $3 \mu 1$ (150-200 ng) of genomic DNA templates. The thermal Cycler 96-Labmet (USA) was programmed for ISSR marker as: 1 cycle (an initial denaturing step) of $5 \mathrm{~min}$ at $94^{\circ} \mathrm{C}, 40$ cycles of $30 \mathrm{sec}$ at $94^{\circ} \mathrm{C}$ (denaturation step), $30 \mathrm{sec}$ at $43^{\circ} \mathrm{C}$ to $61^{\circ} \mathrm{C}$ (annealing step, optimized for each primer), 2 min $30 \mathrm{sec}$ at $72^{\circ} \mathrm{C}$ (elongation step) and $5 \mathrm{~min}$ at $72^{\circ} \mathrm{C}$ (final extension), then stored at $8^{\circ} \mathrm{C}$. The program for SRAP markers was as following: 5 cycles comprising $1 \mathrm{~min}$ at $94^{\circ} \mathrm{C}$ (denaturation), 1 $\min$ at $35^{\circ} \mathrm{C}$ (annealing) and $1 \mathrm{~min} 30$ sec at $72^{\circ} \mathrm{C}$ (elongation), in the following 35 cycles, denaturation at $94^{\circ} \mathrm{C}$ for $1 \mathrm{~min}$, annealing at $47^{\circ} \mathrm{C}$ to $56^{\circ} \mathrm{C}$ for $1 \mathrm{~min}$ and elongation at $72^{\circ} \mathrm{C}$ for $2 \mathrm{~min}$, ending with an elongation step for $10 \mathrm{~min}$ at $72^{\circ} \mathrm{C}$. The amplified products were electrophoresed in a $1-1.5 \%$ agarose gel stained with $0.2 \mu 1$ ethidium bromide. The amplified fragments were visualized and photographed using UVP Bio Doc-It imaging system (USA) Sambrook et al.(1989). ISSR and SRAP techniques were conducted using 9 primers and 11 primer combinations, respectively (Table 2 ). 
Table 2. Primers and their sequences of the SRAP and ISSR molecular markers used in this study.

\begin{tabular}{|l|c|c|c|}
\hline $\begin{array}{c}\text { Primers } \\
\text { name }\end{array}$ & $\begin{array}{c}\text { Primer Sequence } \\
\left(\mathbf{5}^{\prime}-\mathbf{3}^{\prime}\right)\end{array}$ & Primers name & $\begin{array}{c}\text { Primer } \\
\text { Sequence }\left(\mathbf{5}^{\prime}-\mathbf{3}^{\prime}\right)\end{array}$ \\
\hline ME-1(F) & TGAGTCCAAACCGGATA & UBC-815 & $(\mathrm{TC})_{8} \mathrm{~A}$ \\
\hline ME-2(F) & TGAGTCCAAACCGGAGC & UBC-825 & $(\mathrm{AC})_{8} \mathrm{~T}$ \\
\hline ME-4(F) & TGAGTCCAAACCGGACC & UBC-834 & $(\mathrm{GA})_{8} \mathrm{TT}$ \\
\hline ME-7(F) & TGAGTCCAAACCGGACG & UBC-834-1 & $(\mathrm{AG})_{8} \mathrm{YT}$ \\
\hline ME-9(F) & TGAGTCCAAACCGGTGC & UBC-846 & $(\mathrm{CA})_{8} \mathrm{AT}$ \\
\hline EM-3(R) & GACTGCGTACGAATTGAC & UBC-848 & $(\mathrm{CA})_{8} \mathrm{AG}$ \\
\hline EM-5(R) & GACTGCGTACGAATTAAC & UBC-849 & $(\mathrm{GT})_{8} \mathrm{YA}$ \\
\hline EM-6(R) & GACTGCGTACGAATTGCA & UBC-852 & $(\mathrm{GATA})_{2}(\mathrm{GACA})_{2}$ \\
\hline EM-8(R) & GACTGGGTACGAATTCGA & UBC-876 & $(\mathrm{GGGGT})_{3} \mathrm{G}$ \\
\hline EM-9(R) & GACTGGGTACGAATTCAC & & \\
\hline EM-10(R) & GACTGGGTACGAATTCCA & & \\
\hline
\end{tabular}

Data of molecular markers analysis

The DNA banding patterns generated by ISSR and SRAP were analyzed by computer program Gene Profiler software (version 4.03). The presence (1) or absence (0) of each band was recorded for each genotype for all studied primers. Genetic similarity was estimated according to Jaccard (1908). To measure the informativeness of the ISSR and SRAP markers techniques, the polymorphic information content (PIC) was calculated according to the formula of Ghislain et al. (1999) as PIC = 1- [(p) $\left.{ }^{2}+(q)^{2}\right]$ where $p$ is the frequency of allele band present and $q$ is frequency of allele band absent across the tested genotypes.

The marker index (MI) was calculated for each ISSR and SRAP primer as $\mathrm{MI}=\mathrm{PIC} \times \eta \beta$, where $\mathrm{PIC}$ is the mean PIC value, $\eta$ the number of bands, and $\beta$ is the proportion of polymorphism Powell et al. (1996). Analysis of variance (ANOVA) was conducted using the $0-1$ data. The association analysis was conducted using simple linear regression. For this, data on individual phenotypic traits were regressed on whole 0-1 binary marker data for each individual phenotypic marker using Excel programme. The coefficient of determination $\left(\mathrm{R}^{2}\right)$ was calculated as $\mathrm{R}^{2}$ $=1-(\mathrm{SSE} / \mathrm{SST})$, where $\mathrm{SSE}$ is the sum of squares of error and SST is the total sum of squares.

\section{Dendogram construction}

The genetic similarities among the studied genotypes were computed and UPGMA-dendogram was performed according to Jaccard's coefficient (Jaccard, 1908) using the computional package MVSP version 3.1. A cophenetic matrix was derived from each matrix to test goodness of fit of the clusters by comparing the matrices using Mantel test (Mantel, 1967). Finally, the correlation between SRAP and ISSR, ISSR and morphological traits, SRAP and morphological traits and ISSR, SRAP and morphological traits was calculated using NTSYS-pc version 2.20 (Rohlf, 2000).

\section{Results and Discussion}

SRAP markers analysis

Twenty pairs (forward and reverse) SRAP primers were screened among sorghum genotypes and eleven pairs of them were polymor- 
phic. A total of 77 bands were amplified, of which 39 bands $(50.65 \%)$ were polymorphic (Table 3 ). The polymorphic band numbers ranged from 1 (ME1F-EM3R) to 6 bands (ME4FEM10R and ME9F-EM8R).The percentage of polymorphism $(\% \mathrm{P})$ was between $25 \%$ and $86 \%$, detected by ME2F-EM8Rand ME4F-EM10R primers combinations, respectively, with an average of $51.37 \%$. The average number of total bands and polymorphic bands were 7.00 and 3.54per primer, respectively. The size of polymorphic bands ranged from $100 \mathrm{bp}$ ME9F-EM9R and ME9F-EM8R to 1490 bp ME7F-EM6R. In this regard, Robarts and Wolfe (2014) documented an average of $\% \mathrm{P}$ which was $68.7 \%$ across some sorghum genotypes. We note that the mean of $\% \mathrm{P}$ in our study was in agreement with the results of El-Hussein et al. (2014) that showed an average of polymorphism of $48.5 \%$ detected between 33 sorghum accessions.
The polymorphism information content (PIC) index has been used extensively in many genetic diversity studies (Tatikonda et al. 2009; Thudi et al. 2010). The PIC value of markers indicates the usefulness of DNA markers for gene mapping, molecular breeding and germplasm evaluation (Peng and Lapitan, 2005). In this study, the PIC values for SRAP primer combinations varied from 0.09 (ME2F-EM8R)to 0.36 (ME4FEM10R) with an average of 0.17 . The average of PIC values of this work is lower than that of 0.56 which observed among 142 sweet sorghum accessions (Lekgari and Dweikat, 2014). Also El-Hussein et al. (2014) showed that the PIC values between 33 sorghum accessions ranged from 0.23 to 0.93 . The SRAP primers combinations showed that the marker index (MI) values were from 0.12 (ME1F-EM3R) to 2.16 (ME4FEM10R) with an average of 0.68 for the primer combinations (Table 3 ).

Table 3. SRAP markers, total number of fragment detected by each pair of primers, \%P, PIC, MI, RP and fragments sizes.

\begin{tabular}{|c|c|c|c|c|c|c|c|}
\hline \multirow{2}{*}{$\begin{array}{c}\text { Primer } \\
\text { combinations }\end{array}$} & \multicolumn{2}{|c|}{ Amplified bands } & \multirow{2}{*}{$\% \mathrm{P}$} & \multirow{2}{*}{ PIC } & \multirow{2}{*}{ MI } & \multicolumn{2}{|c|}{ Fragments size } \\
\hline & $\begin{array}{c}\text { Bands } \\
\text { number }\end{array}$ & $\begin{array}{c}\text { Polymorphic } \\
\text { bands }\end{array}$ & & & & Larger (bp) & Smaller (bp) \\
\hline ME2F-EM3R & 6 & 3 & 50.00 & 0.16 & 0.48 & 690.00 & 230.00 \\
\hline ME7F-EM6R & 5 & 3 & 60.00 & 0.15 & 0.45 & 1490.00 & 300.00 \\
\hline ME4F-EM10R & 7 & 6 & 86.00 & 0.36 & 2.16 & 700.00 & 150.00 \\
\hline ME4F-EM6R & 5 & 2 & 40.00 & 0.16 & 0.32 & 630.00 & 160.00 \\
\hline ME4F-EM8R & 8 & 3 & 37.50 & 0.17 & 0.51 & 730.00 & 150.00 \\
\hline ME1F-EM5R & 9 & 4 & 44.44 & 0.15 & 0.60 & 1345.00 & 120.00 \\
\hline ME9F-EM6R & 6 & 4 & 66.67 & 0.24 & 0.96 & 720.00 & 230.00 \\
\hline ME9F-EM9R & 11 & 5 & 45.45 & 0.11 & 0.55 & 720.00 & 100.00 \\
\hline ME9F-EM8R & 10 & 6 & 60.00 & 0.19 & 1.14 & 580.00 & 100.00 \\
\hline ME1F-EM3R & 2 & 1 & 50.00 & 0.12 & 0.12 & 150.00 & 110.00 \\
\hline ME2F-EM8R & 8 & 2 & 25.00 & 0.09 & 0.18 & 640.00 & 200.00 \\
\hline Total & 77 & 39 & & & & & \\
\hline Mean & 7.00 & 3.54 & 51.37 & 0.17 & 0.68 & & \\
\hline
\end{tabular}




\section{ISSR markers analysis}

ISSR technique was applied using 15 primers for amplification of the seven genotypes of sorghum. Nine primers proved their ability in giving polymorphic ISSR products. A total of 36 bands were polymorphic, and the $\% \mathrm{P}$ ranged from 25 (UBC825 primer) to 70 (UBC-846 primer) with an average of $53.03 \%$ (Table 4 ). In this regard, Patil et al. (2018) mentioned that out of 288 scorable ISSR markers, 262 were polymorphic. The number of polymorphic bands ranged from 1 (UBC-825) to 7 (UBC 846) with an average of approximately 4 bands per primer. The bands size ranged from $160 \mathrm{bp}$ to $970 \mathrm{bp}$ generated by UBC-834 primer. The $\% \mathrm{P}$ using ISSR in the previous studies was varied. In the same direction, Medraoui et al. (2007) reported a high $\% \mathrm{P}$ of $98 \%$ among 33 sorghum of northwestern Morocco. Also, Taher et al. (2015) documented a high $\% \mathrm{P}(96.51 \%)$ among ten sorghum species. Moreover, Nada et al. (2016) and Patil et al. (2018) obtained \%P of $81 \%$ and $90.97 \%$, respectively. The ISSR primers used in this study were composed of di-, tetra- and pentanucleotide repeat sequences. In this study, the di-nucleotide repeat primers showed the highest level of polymorphism. The UBC-849, UBC-848 and UBC-846 primers belonged to (GT) and (CA) repeats primer groups produced 60, 66 and 70\% polymorphism, respectively (Table 4). It is clear that the highest polymorphism level was obtained in the case of dinucleotide repeat primers. These results are in agreement with those obtained by El-Amin and Nada (2014) and Khaled and Hamam (2015). However, Taher et al. (2015) reported that poly (AG)-anchored primers were more polymorphic and reproducible than other di-nucleotides and tri-nucleotides motifs. Meanwhile, Song et al. (2002) and Sofalian et al. (2008) proposed, the \% $\%$ values were higher when the motifs comprise three to five nucleotides in wheat genotypes.

The PIC values of ISSR data are between 0.03 and 0.24 with an average of 0.16 . The lowest and highest PIC indices were recorded for UBC825, UBC-846 and UBC-849, respectively (Table 4). The average PIC values of ISSR primers are lower than those of previous studies, 0.85 and 0.41 obtained by Chakraborty et al. (2011) and Taher et al. (2015). In addition, Najaphy et al. (2011) reported that the moderate values of PIC for ISSR primers could be attributed to the diverse nature of genotypes and/or highly informative ISSR markers. The marker index (MI) for ISSRs values ranged from 0.03 to 1.68 for UBC-825 and UBC-846, respectively with an average of 0.73 . 
Table 4. ISSR markers, total number of fragment detected by each primer, \%P, PIC, MI and fragments sizes.

\begin{tabular}{|c|c|c|c|c|c|c|c|}
\hline \multirow{2}{*}{$\begin{array}{c}\text { Primer } \\
\text { name }\end{array}$} & \multicolumn{2}{|c|}{ Amplified bands } & \multirow[b]{2}{*}{$\% \mathbf{P}$} & \multirow[b]{2}{*}{ PIC } & \multirow[b]{2}{*}{ MI } & \multicolumn{2}{|c|}{ Fragments size } \\
\hline & Bands number & Polymorphic bands & & & & $\begin{array}{c}\text { Larger } \\
\text { (bp) }\end{array}$ & $\begin{array}{c}\text { Smaller } \\
\text { (bp) }\end{array}$ \\
\hline UBC-846 & 10 & 7 & 70.00 & 0.24 & 1.68 & 500 & 190 \\
\hline UBC-815 & 7 & 3 & 42.86 & 0.10 & 0.30 & 880 & 320 \\
\hline UBC-834-1 & 6 & 3 & 50.00 & 0.18 & 0.54 & 700 & 340 \\
\hline UBC-849 & 5 & 3 & 60.00 & 0.24 & 0.72 & 600 & 250 \\
\hline UBC-852 & 9 & 5 & 55.56 & 0.14 & 0.70 & 820 & 320 \\
\hline UBC-825 & 4 & 1 & 25.00 & 0.03 & 0.03 & 620 & 340 \\
\hline UBC-876 & 7 & 4 & 57.14 & 0.17 & 0.68 & 670 & 230 \\
\hline UBC-848 & 6 & 4 & 66.67 & 0.17 & 0.68 & 650 & 250 \\
\hline UBC-834 & 12 & 6 & 50.00 & 0.20 & 1.20 & 970 & 160 \\
\hline Total & 66 & 36 & & & 73 & & \\
\hline Mean & 7.33 & 4 & 0.03 & 0.1 & 0 & & \\
\hline
\end{tabular}

\section{Single marker analysis}

The present study involved a set of seven sorghum genotypes, exhibiting moderate to high genetic variability for the 8 phenotypic traits included in this work. Using simple linear regression method, a total of 39 polymorphic SRAP molecular markers were identified; four of them were significantly associated with some studied traits.

The results of SMA showed that the SRAP markers ME4EM8 $8_{570 b p}$ and ME4-EM6 $6_{180 b p}$ were regarded as candidate markers linked to grain yield per plant and leaf area per plant, respectively (Table 5 and Figure 1). Moreover, the panicle length was positively linked $(P=0.03)$ to the SRAP marker ME4-EM10 $0_{510 b p}$. Likely, two traits (panicle length and 1000-Grain weight) were regressed significantly on one marker ME1EM5 230bp.
The results in Table 5 showed significant and highly significant regressions $(121.30 *, \quad P=0.018)$, (1.75**, $\quad P=0.0006), \quad\left(23.01^{*}\right.$, $P=0.030), \quad\left(28.74^{* *}, \quad P=0.006\right)$ and $\left(25.85^{* *}, P=0.004\right)$ on $\mathrm{GY} / \mathrm{P}, \mathrm{LA} / \mathrm{P}$, PL, PL and 1000-GW, respectively. Similarly, Khaled and Hamam (2015) reported that the SRAP marker ME7EM6 $_{420 b p}$ was regarded as candidate marker linked to number of kernel/spike in bread wheat. Molecular markers that respond most consistently and to the greatest extent in target environment are the prime candidates for marker-assisted selection (MAS). Therefore, SRAP markers identified during the present study need to be subjected to validation and/or functional analysis of respective traits. In addition, we believe that at least one of the markers identified would be validated and used for MAS. 
Table 5. Analysis of variance (ANOVA) involving simple linear regression $\left(R^{2}\right)$ for traits using 39 SRAP polymorphic bands.

\begin{tabular}{|c|c|c|c|c|c|c|c|}
\hline Marker & Traits & S.V & df & SS & MS & $\overline{\mathbf{R}^{2}}$ & P-value \\
\hline \multirow{3}{*}{ ME4-EM8 } & \multirow{3}{*}{ GY/P } & Genotypes & 1 & 121.30 & $121.30^{*}$ & \multirow{3}{*}{70.70} & \multirow{3}{*}{0.018} \\
\hline & & Error & 5 & 50.28 & 10.06 & & \\
\hline & & Total & 6 & 171.58 & & & \\
\hline \multirow{3}{*}{ ME4-EM6 ${ }_{180 b p}$} & \multirow{3}{*}{$\mathbf{L A} / \mathbf{P}$} & Genotypes & 1 & 1.75 & $1.75^{* *}$ & \multirow{3}{*}{92.11} & \multirow{3}{*}{0.0006} \\
\hline & & Error & 5 & 0.15 & 0.029 & & \\
\hline & & Total & 6 & 1.90 & & & \\
\hline \multirow{3}{*}{ ME4-EM10 $_{510 b p}$} & \multirow{3}{*}{ PL } & Genotypes & 1 & 23.01 & $23.01^{*}$ & \multirow{3}{*}{64.24} & \multirow{3}{*}{0.030} \\
\hline & & Error & 5 & 12.81 & 2.56 & & \\
\hline & & Total & 6 & 35.82 & & & \\
\hline \multirow{6}{*}{ ME1-EM5 $230 \mathrm{bp}$} & \multirow{3}{*}{ PL } & Genotypes & 1 & 28.74 & $28.74 * *$ & \multirow{3}{*}{80.23} & \multirow{3}{*}{0.006} \\
\hline & & Error & 5 & 7.08 & 1.42 & & \\
\hline & & Total & 6 & 35.82 & & & \\
\hline & \multirow{3}{*}{ 1000-GW } & Genotypes & 1 & 25.85 & $25.85^{* *}$ & \multirow{3}{*}{ 83.37 } & \multirow{3}{*}{0.004} \\
\hline & & Error & 5 & 5.16 & 1.03 & & \\
\hline & & Total & 6 & 31.02 & & & \\
\hline
\end{tabular}

$\begin{array}{llllllllll}\text { T1 } & \mathrm{T}_{2} & \mathrm{TH}_{3} & \mathrm{LI} & \mathrm{L} 2 & \mathrm{~L} 3 & \mathrm{~L} 4 & \mathrm{NC} & \mathrm{M}\end{array}$
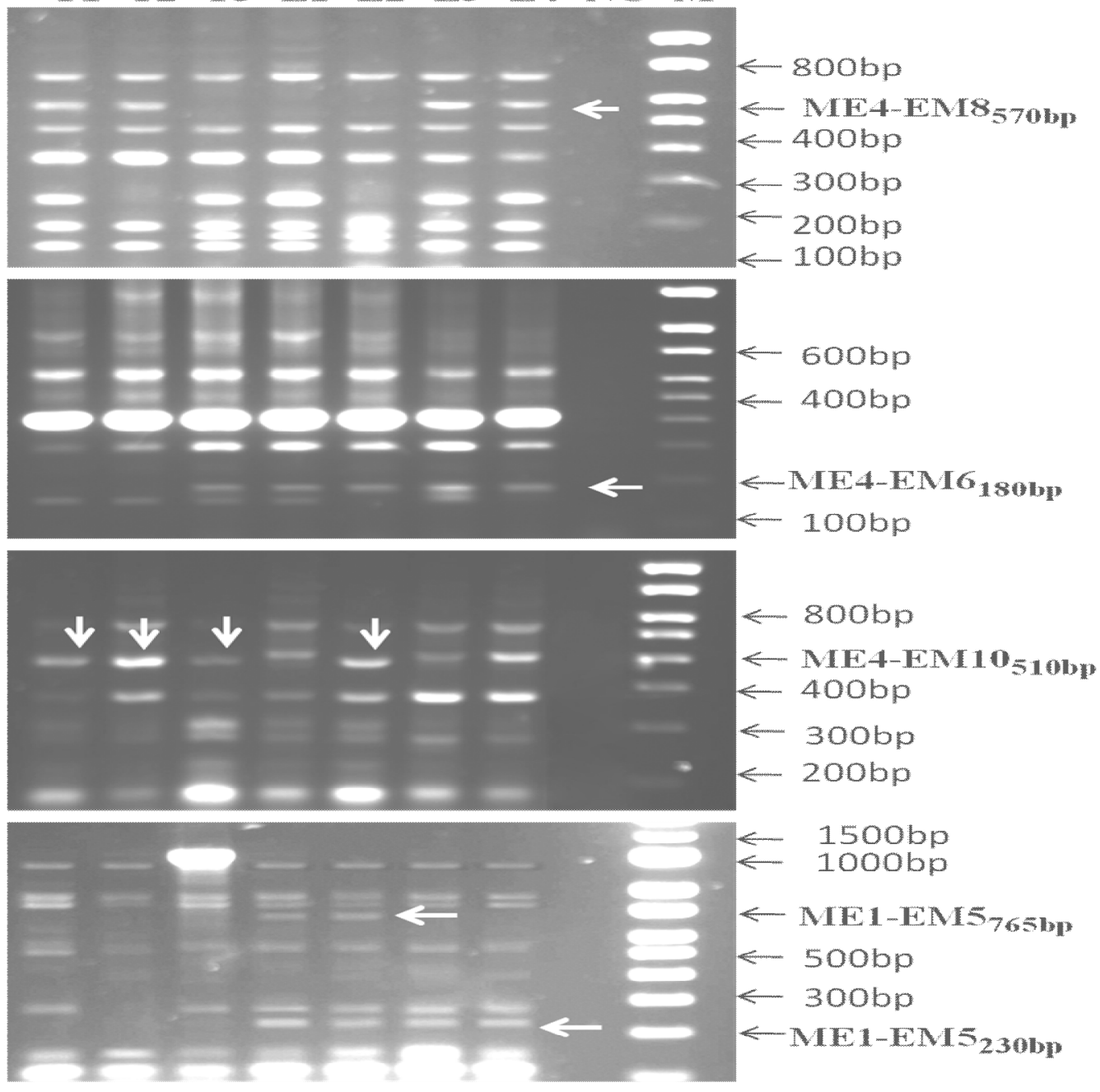

Figure 1. SRAP gel profile showed molecular markers identified in this study. 
Thirty six polymorphic ISSR molecular markers were screened using single marker analysis method; two of these markers were significantly associated with 4 sorghum traits. Results in Table 6 showed that the ISSR marker UBC-834-1 650bp was regarded probably as a candidate marker which linked to leaf area per plant, panicle length and 1000-Grain weight. Moreover, UBC-834-1 ${ }_{\text {700bp }}$ (Figure2) was regarded may be as a candidate marker which linked to number of green leaves.

The results revealed significant and highly significant regression (1.27*, $\mathrm{P}=0.024), \quad\left(28.74^{* *}, \quad p=\right.$ $0.006),\left(25.85^{* *}, p=0.004\right)$ and $(2.82 * *, p=0.0003)$ on leaf area per plant, panicle length, 1000-Grain weight and number of green leaves, respectively. Similarly, Khaled and Hamam (2015) reported that the ISSRs markers; UBC-808 $780 \mathrm{bp}$ and
(UBC-808 $700 \mathrm{bp}$, UBC-81 $11_{870 \mathrm{bp}}$, UBC$819_{980 \mathrm{bp}}$, UBC-845 $1035 \mathrm{bp}$, UBC$880_{1650 \mathrm{bp}}$ ), were regarded as candidate markers, linked to the days to heading and spike length per plant in bread wheat. In the same trend, Khaled et al. (2015) recorded that UBC-81 $1_{850 \mathrm{bp}}$ and UBC-881 $450 \mathrm{bp}$ were regarded probably as candidate markers which were linked to spike length and yield traits, respectively. Moreover, results obtained by Motawea et al. (2015) in bread wheat showed that two markers (UBC-81 $11_{775 \mathrm{bp}}$ and UBC-840 $1530 \mathrm{bp}$ ) were identified for the character viz., 1000-kernal weight trait and two markers UBC-811 $1_{775 p}$ and UBC$840_{535 b p}$ were identified for plant height. The ISSR and SRAP markers identified during the present study need to be subjected to validation and/or functional analysis of respective traits.

Table 6. Analysis of variance (ANOVA) involving simple linear regression $\left(R^{2}\right)$ for traits using 36 ISSR polymorphic bands.

\begin{tabular}{|c|c|c|c|c|c|c|c|}
\hline Marker & Traits & S.V & df & SS & MS & $\mathbf{R}^{2}$ & P-value \\
\hline \multirow{9}{*}{ UBC-834-1 $650 \mathrm{bp}$} & \multirow{3}{*}{$\mathbf{L A} / \mathbf{P}$} & Genotypes & 1 & 1.27 & $1.27 *$ & \multirow{3}{*}{66.74} & \multirow{3}{*}{0.024} \\
\hline & & Error & 5 & 0.63 & 0.13 & & \\
\hline & & Total & 6 & 1.90 & & & \\
\hline & \multirow{3}{*}{ PL } & Genotypes & 1 & 28.74 & $28.74 * *$ & \multirow{3}{*}{80.23} & \multirow{3}{*}{0.006} \\
\hline & & Error & 5 & 7.08 & 1.42 & & \\
\hline & & Total & 6 & 35.82 & & & \\
\hline & \multirow{3}{*}{$\begin{array}{c}\text { 1000- } \\
\text { GW }\end{array}$} & Genotypes & 1 & 25.85 & $25.85 * *$ & \multirow{3}{*}{83.37} & \multirow{3}{*}{0.004} \\
\hline & & Error & 5 & 5.16 & 1.03 & & \\
\hline & & Total & 6 & 31.02 & & & \\
\hline \multirow{3}{*}{ UBC-834-1 $700 \mathrm{bp}$} & \multirow{3}{*}{ No.GL } & Genotypes & 1 & 2.82 & $2.82 * *$ & \multirow{3}{*}{94.33} & \multirow{3}{*}{0.0003} \\
\hline & & Error & 5 & 0.17 & 0.03 & & \\
\hline & & Total & 6 & 3.00 & & & \\
\hline
\end{tabular}




\section{$\begin{array}{lllllllll}\text { T1 } & \text { T2 } & \text { T3 } & \text { L1 } & \text { L2 } & \text { L3 } & \text { L4 } & \text { NC } & \text { M }\end{array}$}

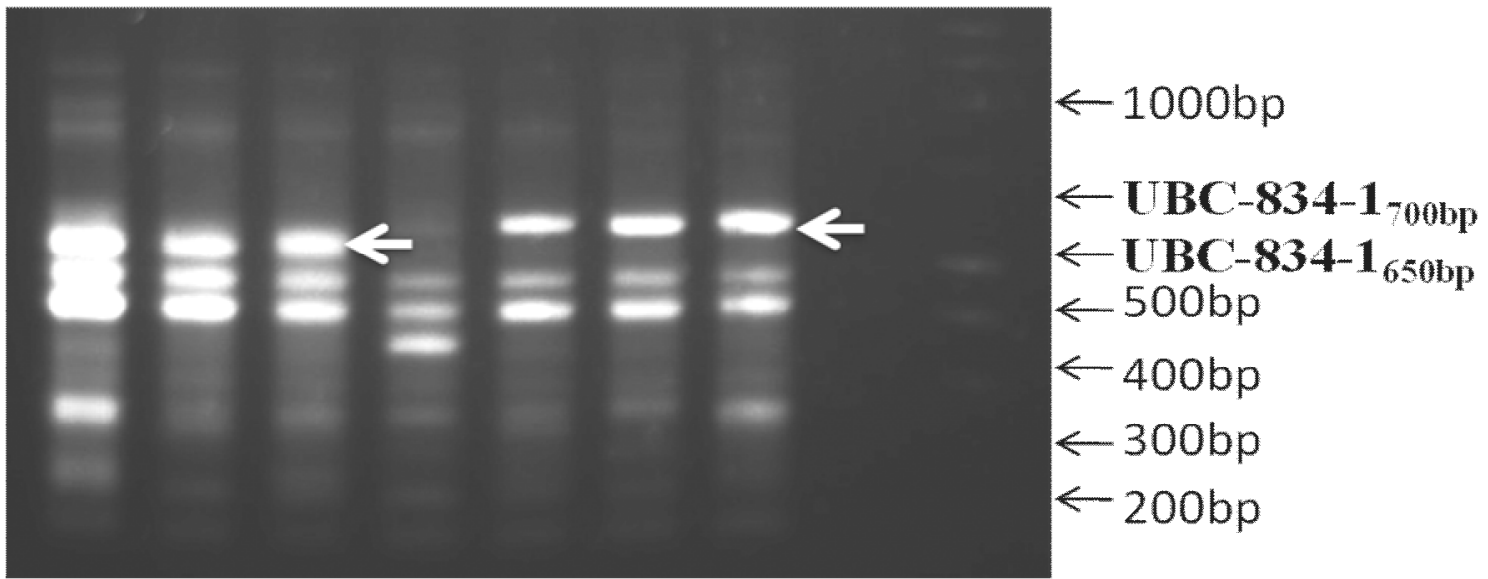

Figure 2. ISSR gel profile showed two molecular markers identified in this study.

\section{Cluster analysis}

A cluster analysis realized using Jaccard's coefficient for the data of SRAP molecular marker, revealed similarity values ranged from $68.5 \%$ (between $\mathrm{T}_{1}$ and $\mathrm{L}_{1}$ ) to $84.7 \%$ (between $\mathrm{T}_{3}$ and $\mathrm{L}_{2}$ ) with an average of $76.6 \%$ (Table 7 below diagonal). The UPGMA cluster analysis based on the SRAP markers separated the studied sorghum parental genotypes into two significantly different clusters. The first cluster was with parental genotypes $\mathrm{T}_{1}$ and $\mathrm{T}_{2}$ at $80.6 \%$ similarity coefficient percent, which branched at similarity percent of $73.4 \%$ with the second cluster and sub-divided into two sub clusters (Figure 3). The first sub-cluster contains genotypes $\mathrm{L}_{3}$ and $\mathrm{L}_{4}$, while the second subcluster contains genotypes $\mathrm{L}_{1}, \mathrm{~L}_{2}$ and $\mathrm{T}_{3}$.

The cluster analysis of ISSR data showed that the percent of similarity using Jaccard's coefficient ranged from $62.7 \%$ (between $\mathrm{L}_{1}$ and $\mathrm{L}_{3}$ ) to $88.2 \%$ (between $\mathrm{T}_{2}$ and $\mathrm{T}_{3}$ ) with an average of $75.5 \%$ (Table 7 above diagonal). The dendogram of ISSR markers gathered the sorghum parental genotypes into two clusters, which separated at $67.2 \%$ percent of similarity. The first big cluster contains six genotypes. The genotype $\mathrm{L}_{3}$ was placed alone on the second cluster. The first big cluster sub-divided into three sub-clusters with genotypes $\mathrm{T}_{1}, \mathrm{~T}_{2}, \mathrm{~T}_{3}, \mathrm{~L}_{2}, \mathrm{~L}_{1}$ and $\mathrm{L}_{4}$ (Figure 4).

Based on the means of morphoagronomical traits (data not shown), the cluster analysis revealed similarity coefficient values ranged from $87.84 \%$ (between $\mathrm{T}_{3}$ and $\mathrm{L}_{4}$ ) to $97.82 \%$ (between $\mathrm{L}_{2}$ and $\mathrm{L}_{3}$ ) with an average of $92.83 \%$ (Table 8 ). The dendogram divided the sorghum parental genotypes into two different clusters which separated at $90.95 \%$ (Figure 5). The first cluster subdivided into three sub-clusters contains five genotypes $\mathrm{T}_{1}, \mathrm{~L}_{4}, \mathrm{~L}_{1}, \mathrm{~L}_{2}$ and $\mathrm{L}_{3}$. The second cluster was with parental genotypes $T_{3}$ and $T_{2}$ at $96.10 \%$ similarity percent, which branched at similarity percent of $90.95 \%$ with the first cluster. 
Website: www.aun.edu.eg/faculty_agriculture/journals_issues_form.php E-mail:ajas@aun.edu.eg

Table 7. Similarity matrix for the seven sorghum parental genotypes according to Jaccard's coefficient obtained from 77 SRAP (below diagonal) and 66 ISSR (above diagonal) fragments.

\begin{tabular}{|c|c|c|c|c|c|c|c|}
\hline $\mathbf{G}$ & $\mathbf{T}_{\mathbf{1}}$ & $\mathbf{T}_{\mathbf{2}}$ & $\mathbf{T}_{\mathbf{3}}$ & $\mathbf{L}_{\mathbf{1}}$ & $\mathbf{L}_{\mathbf{2}}$ & $\mathbf{L}_{\mathbf{3}}$ & $\mathbf{L}_{\mathbf{4}}$ \\
\hline $\mathrm{T}_{1}$ & $\mathbf{1 . 0 0 0}$ & 0.745 & 0.811 & 0.714 & 0.724 & 0.655 & 0.684 \\
\hline $\mathrm{T}_{2}$ & 0.806 & $\mathbf{1 . 0 0 0}$ & 0.882 & 0.778 & 0.754 & 0.655 & 0.745 \\
\hline $\mathrm{T}_{3}$ & 0.806 & 0.754 & $\mathbf{1 . 0 0 0}$ & 0.778 & 0.818 & 0.684 & 0.778 \\
\hline $\mathrm{L}_{1}$ & 0.685 & 0.685 & 0.808 & $\mathbf{1 . 0 0 0}$ & 0.724 & 0.627 & 0.811 \\
\hline $\mathrm{L}_{2}$ & 0.722 & 0.722 & 0.847 & 0.824 & $\mathbf{1 . 0 0 0}$ & 0.724 & 0.786 \\
\hline $\mathrm{L}_{3}$ & 0.761 & 0.712 & 0.763 & 0.744 & 0.803 & $\mathbf{1 . 0 0 0}$ & 0.684 \\
\hline $\mathrm{L}_{4}$ & 0.757 & 0.732 & 0.737 & 0.787 & 0.800 & 0.838 & $\mathbf{1 . 0 0 0}$ \\
\hline
\end{tabular}

Table 8. Similarity matrix among studied sorghum parental genotypes using eight morpho-agronomic traits.

\begin{tabular}{|l|l|l|l|l|l|l|l|}
\hline $\mathbf{G}$ & \multicolumn{1}{|c|}{$\mathbf{T}_{\mathbf{1}}$} & \multicolumn{1}{|c|}{$\mathbf{T}_{\mathbf{2}}$} & \multicolumn{1}{|c|}{$\mathbf{T}_{\mathbf{3}}$} & $\mathbf{L}_{\mathbf{1}}$ & $\mathbf{L}_{\mathbf{2}}$ & $\mathbf{L}_{\mathbf{3}}$ & $\mathbf{L}_{\mathbf{4}}$ \\
\hline $\mathrm{T}_{1}$ & 100.00 & & & & & & \\
\hline $\mathrm{T}_{2}$ & 93.23 & 100.00 & & & & & \\
\hline $\mathrm{T}_{3}$ & 90.69 & 96.10 & 100.00 & & & & \\
\hline $\mathrm{L}_{1}$ & 93.91 & 93.12 & 92.06 & 100.00 & & & \\
\hline $\mathrm{L}_{2}$ & 94.89 & 90.90 & 89.90 & 97.38 & 100.00 & & \\
\hline $\mathrm{L}_{3}$ & 95.90 & 91.18 & 89.98 & 95.52 & 97.82 & 100.00 & \\
\hline $\mathrm{L}_{4}$ & 96.67 & 90.56 & 87.84 & 93.19 & 94.90 & 96.57 & 100.00 \\
\hline
\end{tabular}

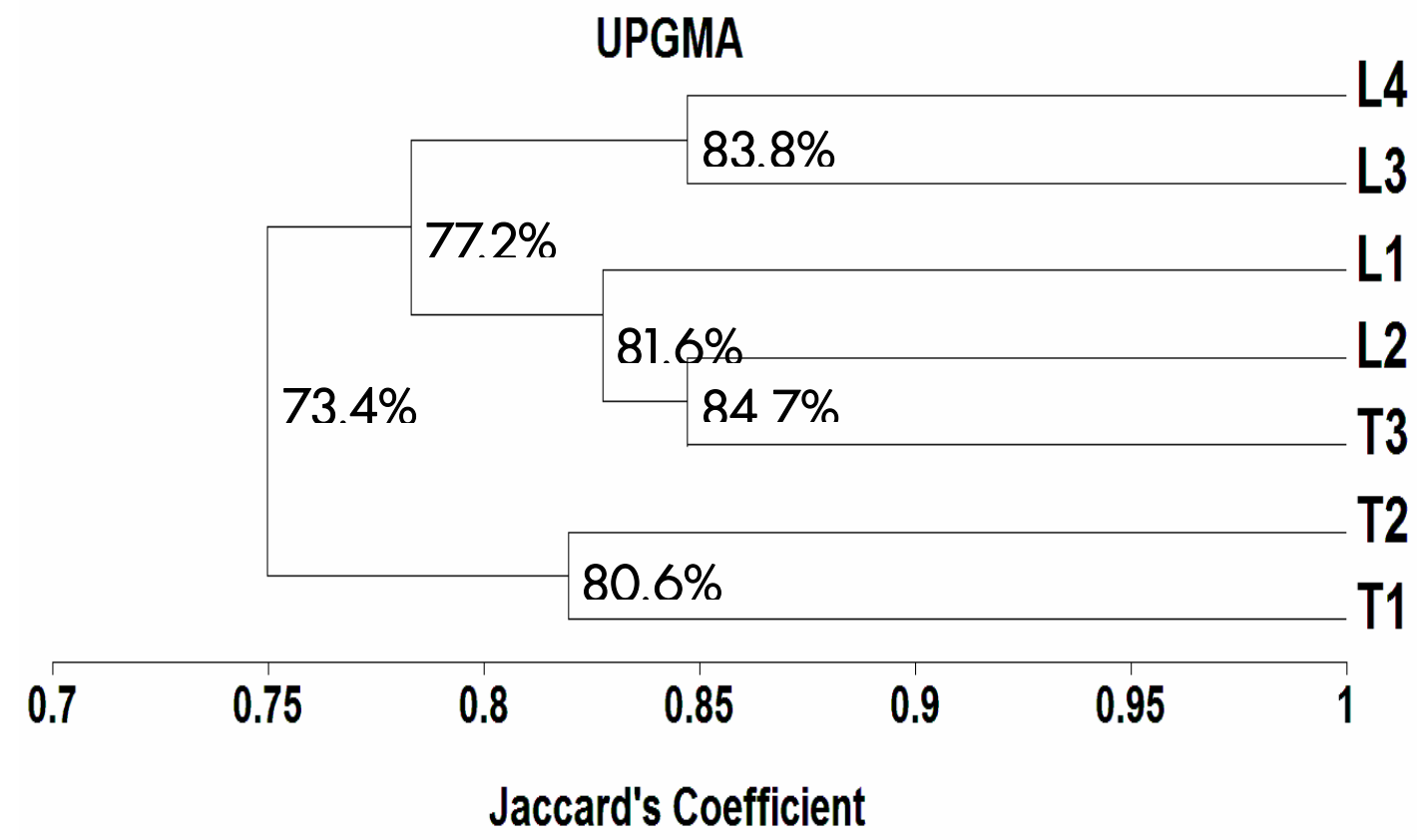

Figure 3. Dendogram of genetic similarities using SRAP data based on Jaccard's coefficient for studied sorghum genotypes. 


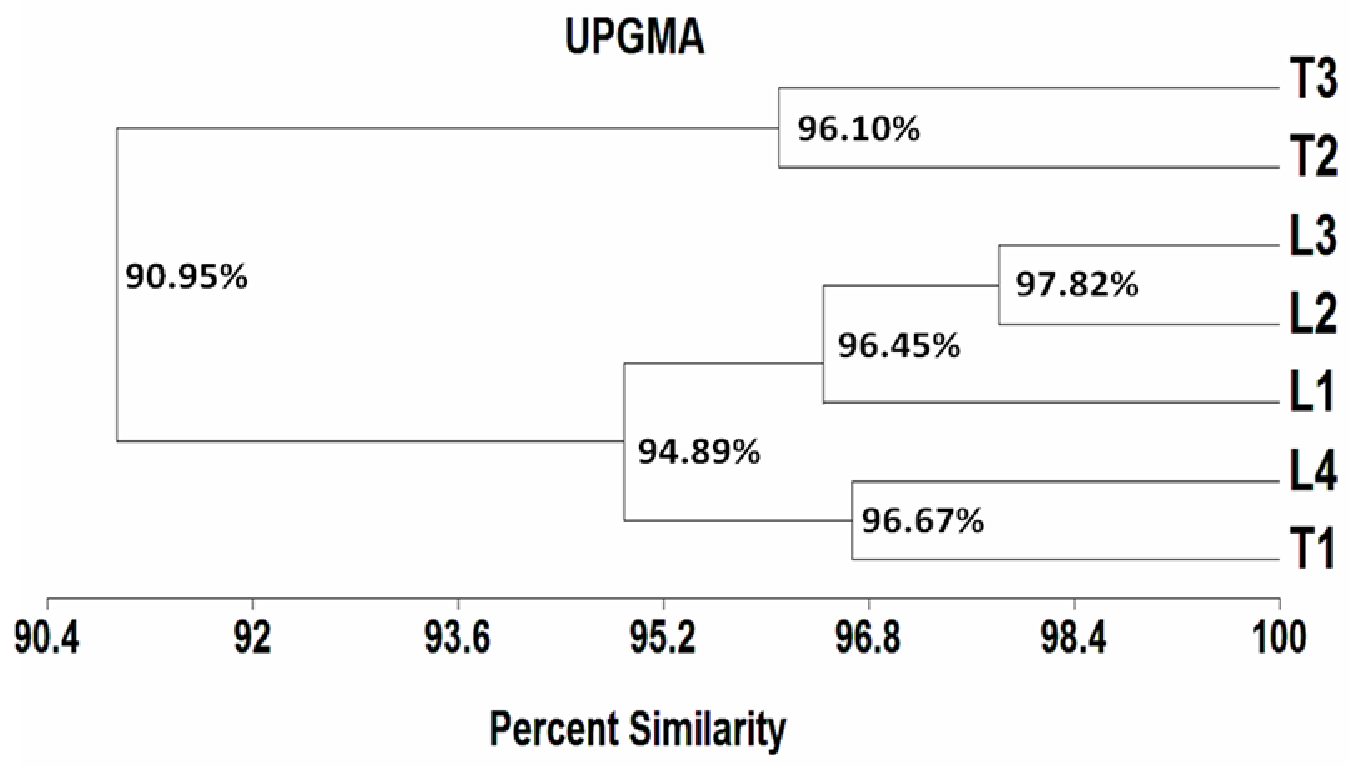

Figure 4. Dendogram of genetic similarities using ISSR data based on Jaccard's coefficient for studied sorghum genotypes.

\section{UPGMA}

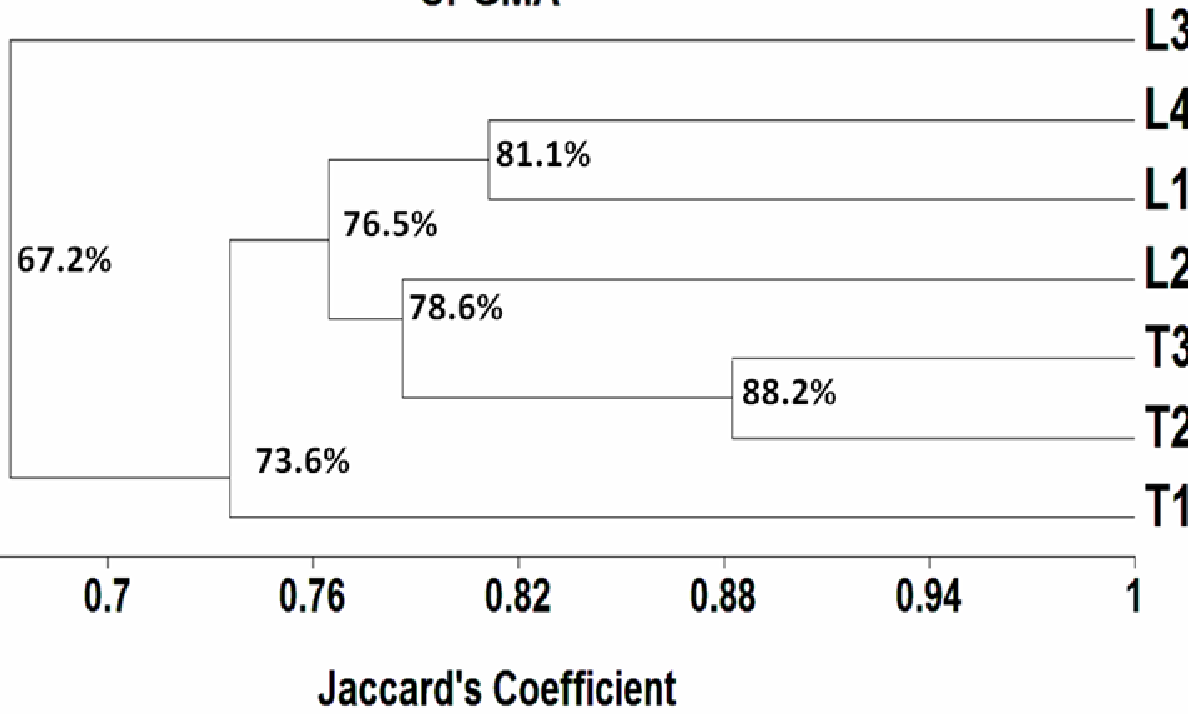

Figure 5. Dendogram of genetic similarities for studied sorghum genotypes using the means of morpho-agronomical traits.

Combined molecular markers and morphological markers

The correlation $(r)$ and the Mantel test statistic $(Z)$ were calculated to measure the degree of relationship between the similarity matrices obtained with SRAP and ISSR data. Results showed that the correlation was positive but insignificant $(\mathrm{r}=0.21$, $P \square$ 0.05). The main reason for the difference between SRAP and ISSR results is that the two marker techniques targeted different parts of the genome. The Mantel test revealed, there was positive and insignificant correlation between the genetic simi- 
larities based on phenotypic data and SRAP marker, $(r=0.19, P>0.05)$. Furthermore, correlation between the genetic similarities based on phenotypic data and ISSR marker was calculated. The Mantel test revealed, there was negative and nonsignificant correlation $(\mathrm{r}=-0.26$, $P>0.05$ ). In addition, correlation between the two similarity matrices generated by the data of morphological traits and molecular markers was calculated. The Mantel test showed, there was positive and insignificant correlation between the genetic similarities based on phenotypic data and the similarity data based on SRAP and ISSR markers, $(\mathrm{r}=0.26$, $P>0.05)$. Roldan-Ruiz et al. (2001) found negative correlation $(-0.06)$ in perennial ryegrass varieties. Pandey et al. (2008) showed that DNA markers are preferable to morphological ones because the relate variability directly at genetic level and provide reliable and enormous data that permit a reproducible estimate of genetic diversity in the germplasm.

Finally, the optimal strategies of the breeding system require extensive knowledge of the breeding materials employed. Results presented here will be useful to understand the current status of genetic diversity between sorghum genotypes. Genetic markers like SRAPs and ISSRs may accurately assay the degree of genetic change between two genomes, but they may not necessarily reflect the divergence in terms of changes in traits of agronomic importance.

\section{References}

Abdi, A.; E. Bekele; Z. Asfaw and A. Teshome. 2002. Patterns of morphological variation of sor- ghum [Sorghum bicolor (L.) Moench] landraces in qualitative characters in North Showa and South Welo, Ethiopia.Hereditas, 137: 161-172.

Ayana, A.; E. Bekele and T. Bryngelsson. 2000. Genetic variation in wild sorghum (Sorghum bicolor ssp. Verticilliforum (L.) Moench) germplasm from Ethiopia assessed by random amplified polymorphic DNA (RAPD). Hereditas, 132: 249254.

Bucheyeki, T. L.; C. Gwanama; M. Mgonja; M. Chisi; R. Folkertsma and R. Mutegi. 2009. Genetic variability characterisation of Tanzania sorghum landraces based on Simple Sequence Repeats (SSRs) molecular and morphological markers. Afr. Crop Sci. J., 17: 71-86.

Chakraborty, S.; I. Thakare; R. Ravikiran; V. Nikman; R. Trivedi; N. Sasidharan and G. C. Jadeja. 2011. Assessment of diversity using RAPD and ISSR markers in Sorghum varieties across Gujarat, India. Electron. J. Plant Breed., 2: 488-493.

Cochran, W. G. and G. M. Cox. 1957. Experimental design. John wiley and Sons, New York: 615p.

Doggett, H. 1988. Utilization of grain sorghum. Sorghum/ long man group UK Limited, Essex, England: 428-475.

El-Amin, H. K. A. and B. H. Nada. 2014. Inter simple sequence repeats polymorphism in Sudanese Sorghum bicolor (L.) Moench accessions. British Biotechnol. J., 4: 846-857. 
El-Hussein, A. A.; A. E. Marmar; Abdalla, W. H.; I. Dweikat and S. Baenziger. 2014. SSR and SRAP markers-based genetic diversity in Sorghum (Sorghum bicolor (L.) Moench) accessions of Sudan. Int. J. Plant Breed. Genet., 8: 89-99.

FAOSTAT.

2017.

Http://www.fao.org.

Ghislain, M.; D. Zhang; D. Fajardo; Z. Hanuman and R. Hijmans. 1999. Marker assisted sampling of the cultivated Andean potato (Solanumphureja) collection using RAPD markers. Genet. Resour. Crop Ev., 46: 547-555.

Gomez, K. A. and A. A. Gomez. 1984. Statistical procedures for agricultural research. John wiley and Sons, New York: 680p.

Jaccard, P. 1908. Nouvelles recherché sur la distribution florale. Bulletin de la SocieteVandoise des Sciences Naturelles, 44: 223270.

Jahufer, M. Z. Z. and F. I. Gawler. 2000. Genotypic variation for seed yield components in white clover (Trifoliumrepens L.). Aust. J. Agric. Res., 51: 657663.

Khaled, A. G. A. and K. A. Hamam. 2015. Association of molecular markers with phenotypic traits of Bread Wheat genotypes. Egypt. J. Genet. Cytol., 44: 115130.

Khaled, A.G. A.; M. H. Motawea and A. A. Said. 2015. Identification of ISSR and RAPD markers linked to yield traits in bread wheat under normal and drought conditions. Genet. Eng. Biotech. J., 13: 243-252.
Lekgari, A. and I. Dweikat. 2014. Assessment of genetic variability of 142 sweet Sorghum germplasm of diverse origin with molecular and morphological markers. Open Eco. J., 4: 371393.

Mantel, N. 1967. The detection of disease clustering and a generalized regression approach. Cancer Res., 27: 209-220.

Medraoui, L.; M. Ater; O. Benlhabib; D. Msikine and A. FilaliMaltouf. 2007. Evaluation of genetic variability of Sorghum (Sorghum bicolor L. Moench) in northwestern Morocco by ISSR and RAPD markers. $C . R$. Biologies, 330: 789-797.

Motawea, M. H.; A. A. Said; A. G. A. Khaled. 2015. ISSR markerstrait associations and stability analysis in bread wheat varieties. Plant Breed. Biotech., 3: 167-177.

Nada, B. H.; A. E. Idris; I. I. Elmunsor; A. I. A. Ibrahim and A. I. Abuali. 2016. Drought tolerance assessment in grain Sorghum (Sorghum bicolor (L.) Moench) genotypes using agromorphological traits and DNA markers. Inter. J. Plant Breed. Genet., 10: 125-131.

Najaphy, A.; R. A. Parchina and E. Farshadfara. 2011. Evaluation of genetic diversity in wheat cultivars and breeding lines using inter simple sequence repeat markers. Biotechnol. Biotechnol. Equip., 25: 2634-2638.

Pandey, S.; S. Kumar; M. Rai; U. Mishra and M. Singh. 2008. Assessment of genetic diversity in Indian ash gourd (Benincasa- 
hispida) accessions using RAPD markers. Proceedings of $\mathrm{IX}^{\text {th }}$ EUCARPIA meeting on genetics and breeding of Cucurbitaceae (Pitrat M, ed.), INRA, Avignon, France, pp. 59-66.

Patil, S.; D. Salunke and R. Veeraghattapu. 2018. Analysis of genetic diversity using ISSR markers in sorghum bicolor. Book, Lambert Academic Publishing. $148 \mathrm{p}$.

Peng, J. H. and N. L. V. Lapitan. 2005. Characterization of ESTderived microsatellites in the wheat genome development of eSSR markers. Funct. Integr. Genomics, 5: 80-96.

Porebski, S.; L. G. Bailey and B. R. Baum. 1997. Modification of a CTAB DNA extraction protocol for plants containing high polysaccharide and polyphenol components. Plant Mol. Biol. Rep., 15: 8-15.

Powell, W.; M. Morgante; C. Andre; M. Hanafey; J. Vogel; S. Tingey and A. Rafalski. 1996. The comparison of RFLP, RAPD, AFLP and SSR (microsatellite) markers for germplasm analysis. Mol. Breed., 2: 225-238.

Robarts, D. W. H. and D. Wolfe. 2014. Sequence-related amplified polymorphism (SRAP) markers: A potential resource for studies in plant molecular biology. Appl. Plant Sci., 2: 113.

Rohlf, F. J. 2000. NTSYS-pc: Numerical taxonomy and multivariate analysis system. Version 2.1 Exeter Software, Setauket, USA.
Roldan-Ruiz; F. A. Van Eeuwijk; T. J. Gilliland; P. Dubreuil; C. Dillmann; J. Lallemand; M. De Losse and C. P. Baril. 2001. A comparative study of molecular and morphological methods of describing relationships between perennial ryegrass ( $\mathrm{Lo}$ liumperenne L.) varieties. Theor. Appl. Genet., 1203: 1138-1150.

Sambrook, J.; E. F. Fritsch and T. Maniatis. 1989. Molecular cloning: a laboratory manual. $2^{\text {nd }}$ Edition. Cold Spring Harbor, New York: Cold Spring Harbor Laboratory Press.

Sofalian, O.; N. Chaparzadeh; A. Javanmard and M. S. Hejazi. 2008. Study the genetic diversity of wheat landraces from northwest of Iran based on ISSR molecular markers. Inter. J. Agric. Biol., 10: 466-468.

Song, Q. J.; E. W. Fichus and P. B. Cregan. 2002. Characterization of trinucleotide SSR motifs in wheat. Theor. Appl. Genet., 104: 286-293.

Taher, D.; M. Sabbouh and S. lawand. 2015. Genetic diversity analysis of Sorghum (Sorghum bicolor L. Moench) accessions using ISSR markers. Inter. J. Chemtech Research., 8: 350357.

Tatikonda, L.; S. P. Wani; S. Kannan; N. Beerelli; T. K. Sreedevi; D. A. Hoisington; P. Devi and R. A. Varshney. 2009. AFLPbased molecular characterization of an elite germplasm collection of Jatrophacurcas L.: A biofuel plant. Plant Sci., 176: 505-513. 
Thudi, M.; R. Manthena; S. P. Wani; L. Tatikonda; D. A. Hoisington and R. A. Varshney. 2010. Analysis of genetic diversity in Pongamia (Pongamiapinnata L. Pierre) using AFLP markers. $J$. Plant Biochem. Biot., 19: 209216.

Wang, X.; G. Liu; R. Chang; J. Han and E. Guo. 2009. Optimization of annealing temperature of
SRAP-PCR in 5 temperate fruits. Genom. Appli. Biol., 28: 525-528.

Yang, W.; A. C. Olivera; I. Godwin; K. Schertz and J. L. Bennetzen. 1996. Comparison of DNA marker technologies in characterizing plant genome diversity: variability in chinese sorghums. Crop Sci., 36: 1669-1676. 
العلاقة بين الواسمات الجزيئية SRAP و ISSR و الصفات الظاهرية فى بعض التراكيب الور اثيه من الذرة الرفيعة

عبدالصبور جمال عبدالصبور خالد ، جلا أحمد رزق الثربينى و هاير سرحان عبدالغنى عبدالعزيز قسم الور اثة - كلية الزر اعه - جامعة سو هاج

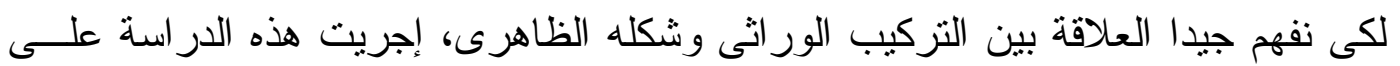

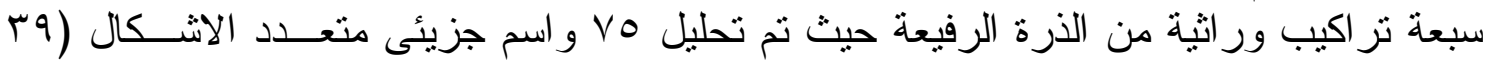

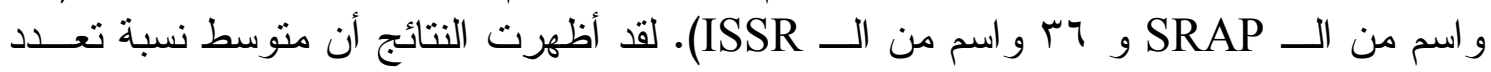

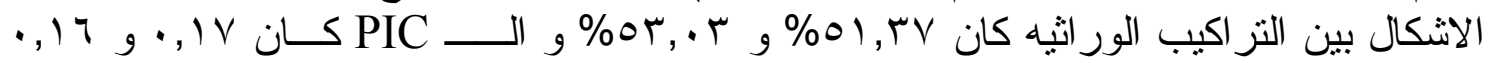

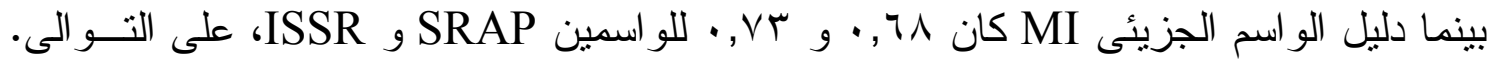

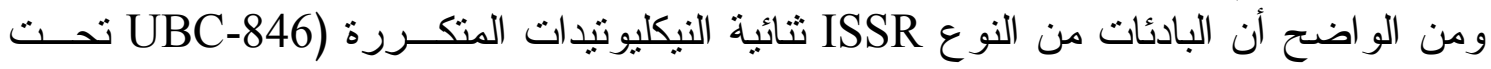

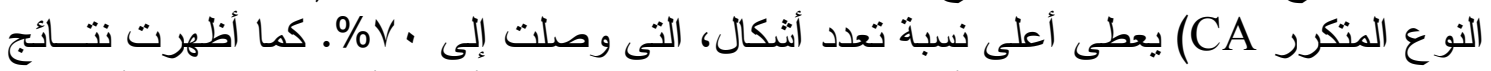

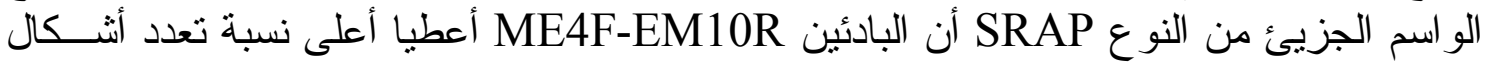

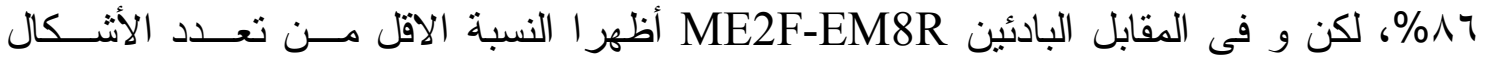

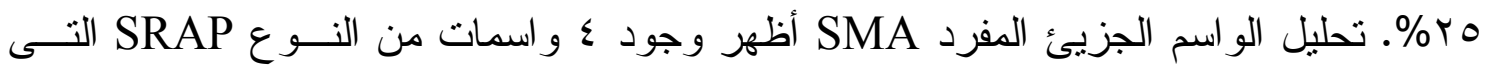

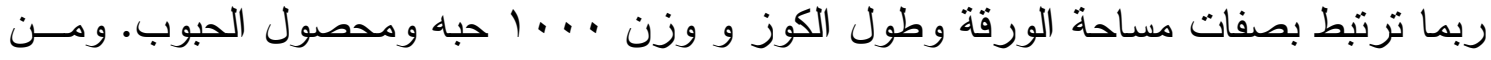

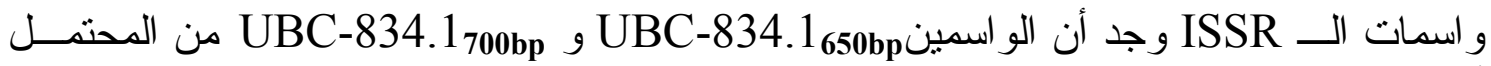

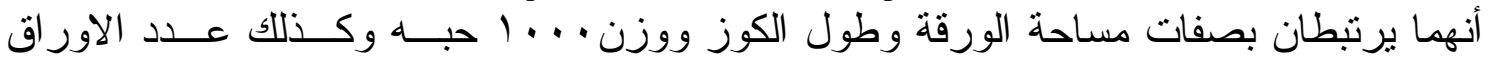

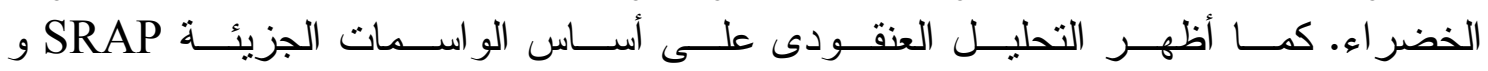
ISSR

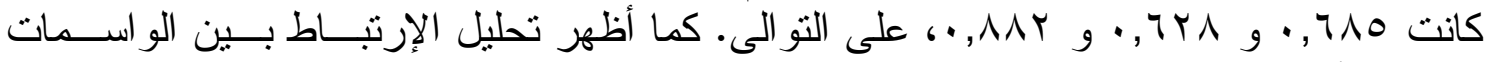
الجزيئية أن معامل الإرتباط كان إيجابيا لكنه غير معنوى. 